Aksaray University
Journal of Science and Engineering
e-ISSN: 2587-1277
http://dergipark.gov.tr/asujse
http://asujse.aksaray.edu.tr

Research Article

\title{
Determination of Groundwater Quality around Seyfe Lake (Kurşehir) using Geographical Information Systems (GIS)
}

\author{
Zeynel Basibuyuk ${ }^{1}$, Gokhan Ekincioglu*,2, Dogukan Dogu Yavasli ${ }^{3}$, \\ ${ }^{1}$ Kırşehir Ahi Evran University, Faculty of Engineering \& Architecture, Geology Engineering, Kırşehir, Turkey \\ ${ }^{2}$ Kırşehir Ahi Evran University, Kaman Vocational School, Drilling Technology, Kırşehir, Turkey \\ ${ }^{3}$ Kırşehir Ahi Evran University, Faculty of Science \& Literature, Geography Department, Kırşehir, Turkey
}

-Received Date: Dec 24, $2019 \quad$-Revised Date: Jan 06, $2020 \quad$-Accepted Date: Jan 14, $2020 \quad$-Published Online: Jun 24, 2020

\begin{abstract}
Groundwater is widely used for both potable water and agricultural purposes in Turkey. In this study, groundwater quality and the factors of contamination with their impact areas has been assessed using geographical information systems and geostatistical techniques at Seyfe Lake, east of Kırşehir province. For this purpose, the samples from groundwater has been chemically analyzed depending on TS 266-2005 and WHO-2006 standards and contamination maps has been prepared using Inverse Distance Weighting (IDW) interpolation techniques. It has been thought that the contaminations at the study area is related with lithology and $\mathrm{NO}_{3}, \mathrm{SO}_{4}, \mathrm{As}, \mathrm{F}$ and $U$ increase depending on unconscious use of fertilizers and pesticides in agriculture. The groundwater that can be used as potable water has been determined around Bozçaldağ formation (marble). Therefore, it has been foreseen that Bozçaldağ formation areas can primarily be preferred for groundwater that will be used as potable water.
\end{abstract}

\section{Keywords}

Groundwater, Geographical Information Systems, Seyfe Lake, Arsenic, Nitrate

*Corresponding Author: Gokhan Ekincioglu, gekincioglu@ahievran.edu.tr 


Aksaray University
Journal of Science and Engineering
e-ISSN: 2587-1277
http://dergipark.gov.tr/asujse
http://asujse.aksaray.edu.tr

Research Article

\title{
Seyfe Gölü Çevresinin (Kurşehir) Yeraltı Suyu Kalitesinin Coğrafi Bilgi Sistemleri (CBS) Kullanılarak Belirlenmesi
}

\author{
Zeynel Başıüyük ${ }^{1}$, Gökhan Ekincioğlu*,2, Doğukan Doğu Yavaşlı \\ ${ }^{1}$ Kırşehir Ahi Evran Üniversitesi, Mühendislik\&Mimarlık Fakültesi, Jeoloji Mühendisliği, Kırşehir, Türkiye \\ ${ }^{2}$ Kırşehir Ahi Evran Üniversitesi, Kaman Meslek Yüksekokulu, Sondaj Teknolojisi, Kırşehir, Türkiye \\ ${ }^{3}$ Kırşehir Ahi Evran Üniversitesi, Fen\&Edebiyat Fakültesi, Coğrafya Bölümü, Kırşehir, Türkiye
}

-Gönderi Tarihi: 24 Ara $2019 \quad$-Düzeltme Tarihi: 06 Oca $2020 \quad$-Kabul Tarihi: 14 Oca $2020 \quad$-Çevrimiçi Yayın Tarih: 24 Haz 2020

\section{Özet}

Türkiye'de hem tarım amaçlı hem de içme suyu olarak yeraltı kaynakları yaygın olarak kullanılmaktadır. Bu çalışmada, coğrafi bilgi sistemleri ve jeoistatistiksel yöntemler kullanarak Kırşehir ilinin doğusunda yer alan tektonik kökenli Seyfe Gölü çevresindeki yeraltı suyu kalitesinin ve kirlenmesine neden olan unsurlar ile etki alanlarının belirlenmesi amaçlanmıştır. Bunun için çalışma alanından alınan yeraltı suyu örneklerinin kimyasal analiz sonuçları TS 266-2005 ve WHO-2006 standartlarına göre değerlendirilmiş ve Inverse Distance Weighting/ Ters Mesafe Ağırlıklı (IDW) enterpolasyon yöntemi kullanarak çalışma alanının kirlilik haritaları hazırlanmıştır. Çalışma alanındaki kirliliğin kayaç litolojisi ile tarımda bilinçsiz olarak kullanılan gübre ve pestisitlerin yol açtığı $\mathrm{NO}_{3}, \mathrm{SO}_{4}$, As, F ve U miktarlarındaki artışla ilgili olduğu düşünülmektedir. Su kalitesi açısından içme suyu olarak kullanılabilecek kalitedeki suların Bozçaldağ formasyonun (mermerler) yayılım gösterdiği alanlarda bulunduğu belirlenmiştir. Bu nedenle bölgede içme suyu olarak kullanılacak yeraltı suyunun temininde Bozçaldağ formasyonun bulunduğu alanların öncelikli olarak değerlendirilebileceği öngörülmektedir.

\section{Anahtar Kelimeler}

Yeraltı suyu, Coğrafi Bilgi Sistemleri, Seyfe Gölü, Arsenik, Nitrat

"Sorumlu Yazar: Gökhan Ekincioğlu, gekincioglu@ ahievran.edu.tr 


\section{GIRİŞ}

Dünya üzerindeki canlı hayatının sürdürülebilmesi için en temel gereklilik olan tatlı su kaynakları (yeraltı suyu, akarsu ve göl) doğal yollar (kayaç litolojisi, maden yatakları vb.) ve insan etkisi ile (sanayileşme, tarım vb.) kirlenmektedir. Tatlı su kaynaklarının verimli bir şekilde kullanılması ve sonraki nesillere kaliteli bir şekilde aktarılması hem insan sağlığı hem de ekosistem açısından büyük önem arz etmektedir.

Tatlı su kaynaklarının kirlenmesine neden olan unsurların ve etki alanlarının belirlenmesi için klasik hidrojeoloji çalışmaları ile birlikte coğrafi bilgi sistemlerinin (CBS) kullanılması elde edilen noktasal verilerin geniş alanlardaki su kalitesini gözlemleme açısından yararlı olmaktadır. Son yıllarda yeraltı suyu [1-4], nehir [5, 6] ve göl [7, 8] gibi farklı su kaynakları kalitesinin değerlendirilmesi çalışmalarında CBS kullanımı yaygınlaşmıştır.

Yeraltı suyu kalitesinin geniş alanlarda haritalanmasında çeşitli CBS tabanlı jeoistatistiksel yöntemler kullanılmaktadır. Jeoistatistik, klasik istatistik yöntemlerinden farklı olarak örnekler arası ilişkiyi, örneklerin konumlarını hesaba katarak ele alan istatistiksel hesaplama yöntemleridir [9]. Jeoistatistiksel enterpolasyon yöntemlerinden Kriging [10], Cokriging [11], Inverse Distance Weighting [12] gibi yöntemler yeraltı su kalitesinin çeşitli örneklem noktalarından elde edilip geniş alanlardaki dağılımın tahmin edilmesinde sıklıkla kullanılmaktadır.

$\mathrm{Bu}$ çalışmada Seyfe Gölü çevresinin (Kırşehir) yeraltı suyu kalitesinin CBS kullanılarak değerlendirilmesi, elde edilen veriler sonrası bölgedeki yeraltı suyu kalitesinin hangi etkenlerden etkilendiği ve sudaki kirliliğe neden olan faktörlerin belirlenmesi amaçlanmıştır.

\section{2. ÇALIŞMA ALANI}

Çalışma alanı Kırşehir ilinin doğusunda, Mucur ilçesinde yer alır. Örnek alımları gerçekleştirilen noktalar 101-115 arasında kodlanmış olup Şekil 1'de verilmiştir. Çalışma alanında bulunan Seyfe Gölü tektonik kökenli bir çukurda bulunan tuzlu bir göldür. Gölü çevreleyen Seyfe Ovası yaklaşık $1500 \mathrm{~km}^{2}$ 'lik kapalı bir havza içinde yer almaktadır. Çalışma alanının 2012 yılı CORINE (Coordination of Information on The Environment) arazi örtüsü haritası incelendiğinde gölü çevreleyen alanların büyük bölümünün sürekli sulanan alanlar olarak sınıflandırıldığı, çalışma alanının doğusunda kalan daha küçük bir alanın ise sulanmayan ekilebilir alanlar olduğu görülmektedir (Şekil 2). Buradaki hem evsel hem de tarımsal su ihtiyacının nerdeyse tamamı gölü besleyen yer altı suyu kaynaklarından sağlamaktadır [13]. 


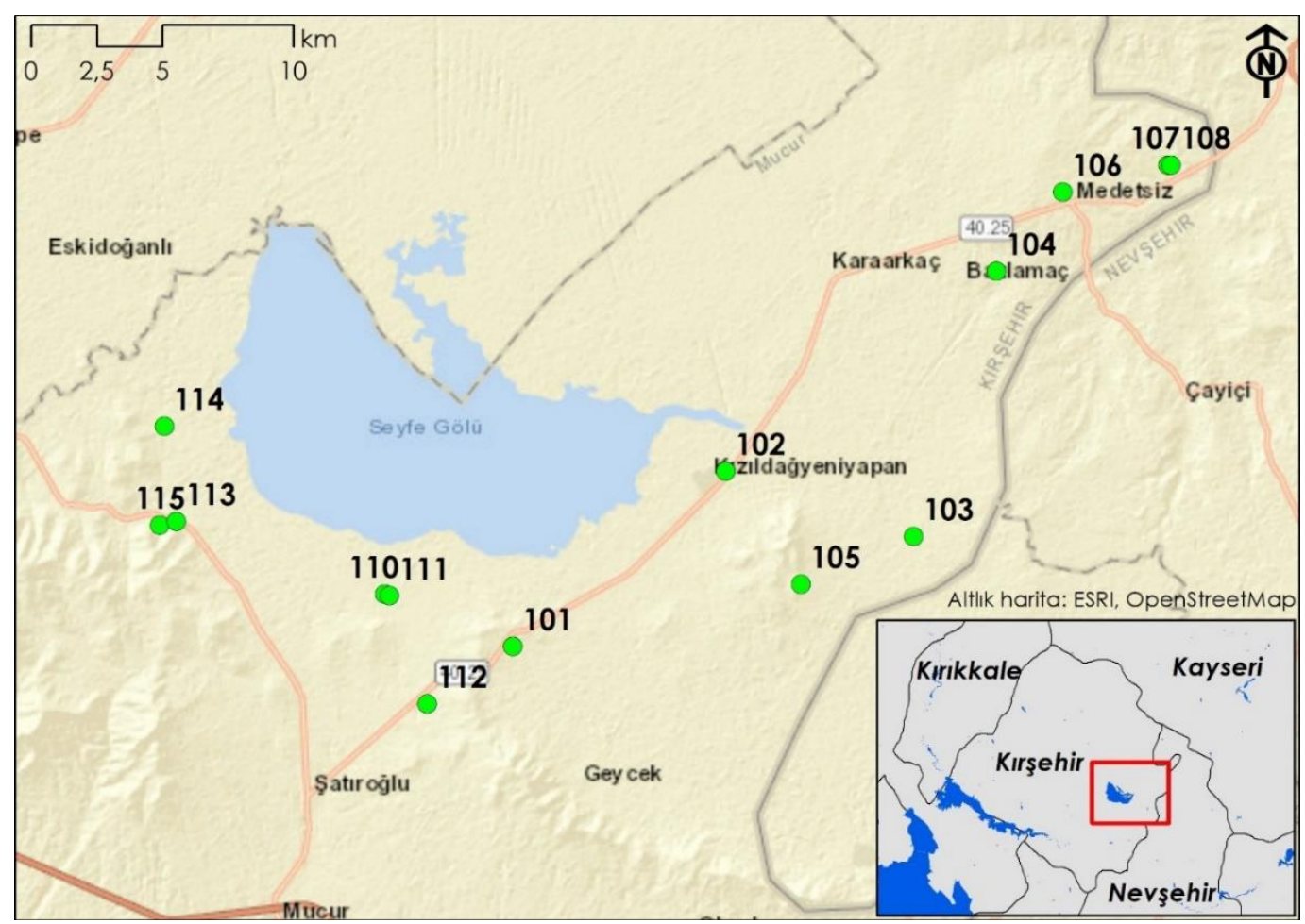

Şekil 1. Çalışma alanının konumu ve örnek alım noktaları

Çalışma sahasındaki en yaşlı seviyeyi şist, gnays, amfibolit ve mermerlerden oluşan Paleozoyik yaşlı Orta Anadolu Metamorfitleri oluşturmakta ve bu birimleri Eosen-Kuvaterner yaşlı sedimanter birimler uyumsuzlukla örtmektedir (Şekil 3). Orta Anadolu Metamorfitleri çalışma alanı içerisinde 3 formasyon olarak gözlenmektedir. Bunlar Kalkanlıdağ, Kervansaraydağ ve Bozçaldağ formasyonlarıdır. Kalkanlıdağ formasyonu, çoğunlukla gnays daha az oranda şistler, kuvarsit ve amfibolitten oluşmaktadır. Kervansaraydağ formasyonu, mermer bant ve mercekleri ile biyotit-muskovitşist, kalksilikatikşist, kalkşist, kuvarsitşist, piroksenşist, amfibolitşist ve daha az oranda gnays, kalksilikatik gnays, kuvarsit, amfibolit, kloritşist ve talk şist içerir. Bozçaldağ formasyonu ise mermerlerden oluşmaktadır [14-15].

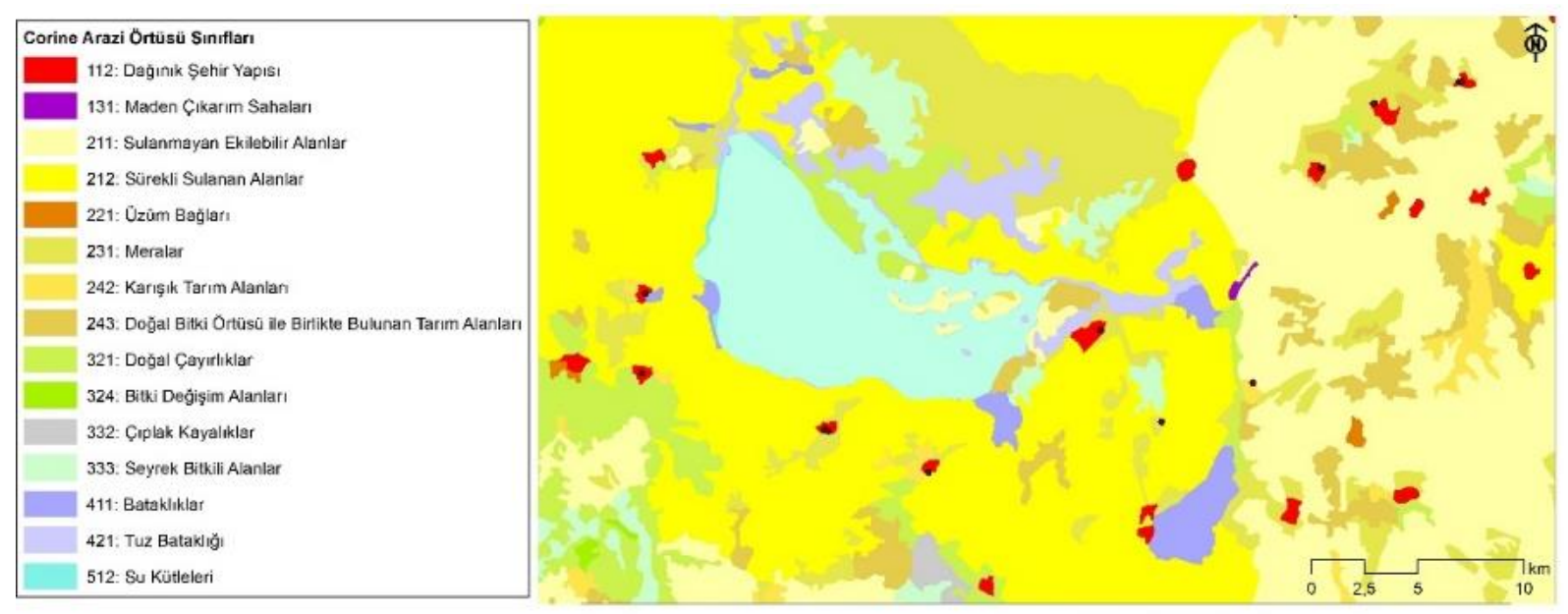

Şekil 2. Seyfe gölü ve çevresinin CORINE (2012) arazi örtüsü haritası 
Çalışma sahasındaki Orta Anadolu Metamorfitleri, Eosen-Kuvaterner yaşlı denizel ve karasal kaya birimleri tarafından örtülmektedir. Çakı1taşı, kumtaşı, silttaşı, kiltaşı, kireçtaşı ve yer yer tüf, jipsli seviyelerin ardalanmasından oluşan bu birimler, yaşlıdan gence doğru, Eosen yaşlı Çevirme Formasyonu içerisinde bulunan Dulkadirli Kireçtaşı Üyesi, Üst Miyosen yaşlı Kızılırmak Formasyonu ile içerisinde bulunan Mucur Tüf Üyesi ve Kozaklı Kireçtaşı Üyesi en üst seviyede Kuvaterner yaşlı alüvyonlardır [14-16].

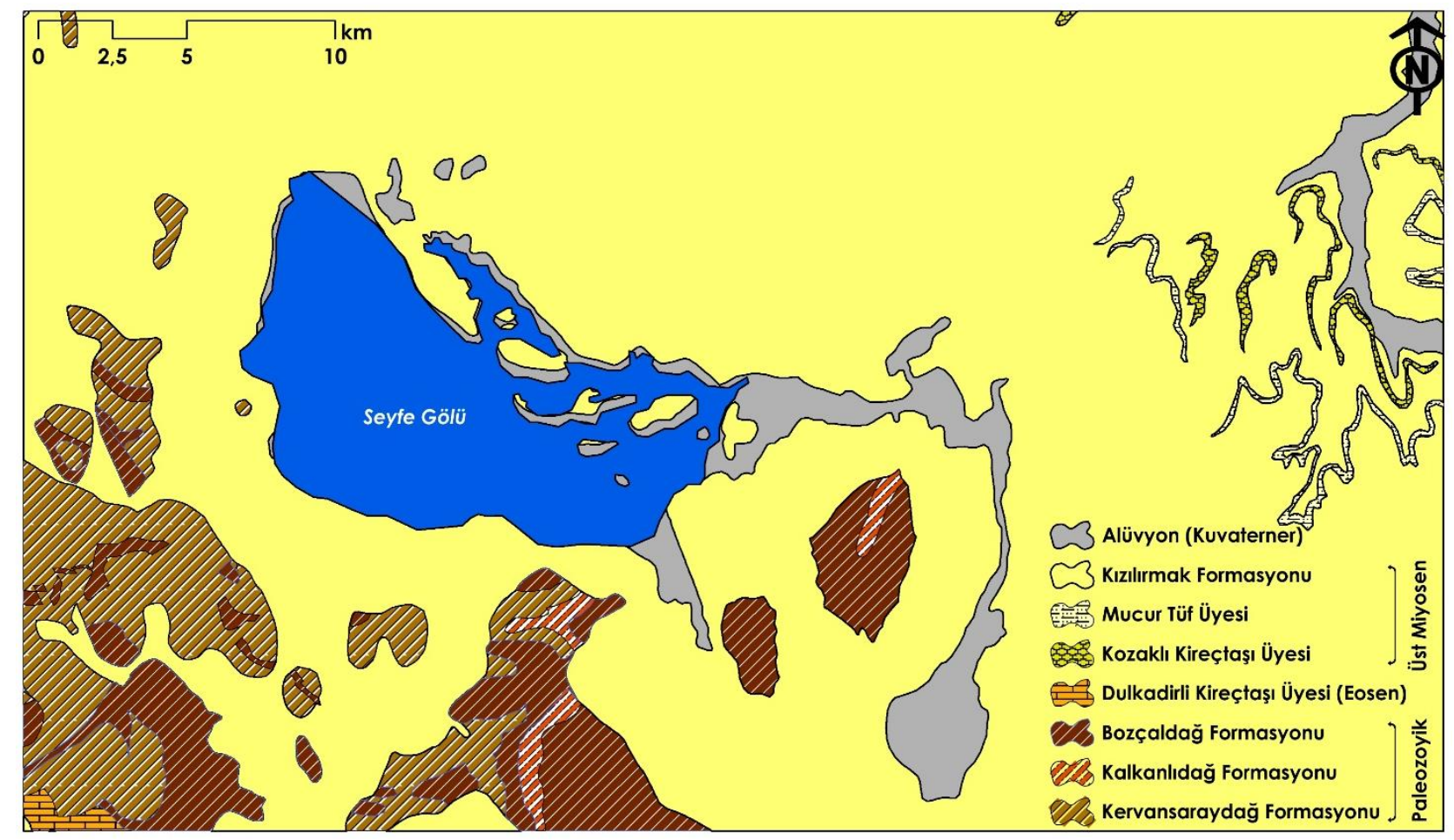

Şekil 3. Seyfe gölü ve çevresinin jeoloji haritası

\section{MATERYAL VE METOT}

Çalışma alanındaki yeraltı sularından (doğal kaynak ve sondaj kuyusu) kurak (Ekim-2017) ve yağışlı (Mart-2018) dönemlerde 14 adet örnek alımı gerçekleştirilmiştir. Örnek alımları gerçekleştirilen noktalar 101-114 arasında kodlanmış olup Şekil 1'de verilmiştir. Kimyasal analizler katyon $(\mathrm{Na}, \mathrm{K}, \mathrm{Mg}, \mathrm{Ca})$ ve anyon $\left(\mathrm{Cl}, \mathrm{NO}_{3}, \mathrm{SO}_{4}, \mathrm{~F}\right)$ değerleri Hacettepe Üniversitesi $\mathrm{Su}$ Kimyası Laboratuvarında ve $\mathrm{As}, \mathrm{Ca}, \mathrm{Cl}, \mathrm{F}, \mathrm{K}, \mathrm{Mg}$, Na ve $\mathrm{U}$ elementleri ise Kocaeli Üniversitesi ICP-MS Laboratuvarında yapılmıştır.

Tatlı su kaynaklarının korunması ve kullanıma uygunluk açısından kalitesinin belirlenmesi amacıyla kullanılan farklı kuruluşlar tarafından oluşturulmuş standartlar bulunmaktadır [1718]. TS 266- 2005 ve WHO-2006 standartlarındaki su içerisinde insan sağlığını etkileyen As, $\mathrm{F}, \mathrm{U}$ elementleri ile $\mathrm{NO}_{3}, \mathrm{SO}_{4}$ bileşiklerinin su kirliliği haritaları yanı sıra $\mathrm{As}, \mathrm{Ca}, \mathrm{Cl}, \mathrm{F}, \mathrm{K}, \mathrm{Mg}$, 
Na ve U elementleri ile $\mathrm{NO}_{3}$ ve $\mathrm{SO}_{4}$ bileşiklerinin yoğunluk haritaları da oluşturulmuştur. Tablo 1'de TSE ve Dünya Sağlık Örgütü içme suyu kalite parametre değerleri verilmiştir.

Tablo 1. TSE ve Dünya Sağl1k Örgütü içme suyu kalite parametre değerleri

\begin{tabular}{|l|c|c|}
\hline \multicolumn{2}{|c|}{ Kabul edilebilir Maksimum Değerler } \\
\hline STANDARTLAR & TS-266-2005 & WHO-2006 \\
\hline Kimyasal $\mathbf{m g} / \mathbf{L}$ & 50 & 50 \\
\hline Nitrat $\left(\mathrm{NO}_{3}\right)$ & 250 & 250 \\
\hline Sülfat $\left(\mathrm{SO}_{4}\right)$ & 200 & 200 \\
\hline Sodyum $(\mathrm{Na})$ & 250 & 250 \\
\hline Klorür $(\mathrm{Cl})$ & - & - \\
\hline Kalsiyum $(\mathrm{Ca})$ & - & - \\
\hline Potasyum $(\mathrm{K})$ & - & - \\
\hline Magnezyum $(\mathrm{Mg})$ & 1.5 & 1.5 \\
\hline Florür $(\mathrm{F})$ & & 10 \\
\hline Kimyasal $\mathbf{U g} / \mathbf{L}$ & 10 & 15 \\
\hline Arsenik $(\mathrm{As})$ & - & \\
\hline Uranyum $(\mathrm{U})$ & & \\
\hline
\end{tabular}

Yoğunluk ve kirlilik haritalarının hazırlanmasında Inverse Distance Weighting / Ters Mesafe Ağırlıklı (IDW) enterpolasyon yöntemi kullanılmıştır. IDW bilinen örnek noktalara ait değerlerden yola çıkarak örneklenmeyen alanlara ait hücre değerlerinin belirlenmesi için kullanılan bir yöntemdir. IDW birbirine yakın olan olguların birbirinden daha uzak olanlara göre daha benzer olduğu varsayımını yapar. Öngörülen yere en yakın olan ölçülmüş değerler, uzak olanlardan daha fazla etkiye sahiptir. IDW, ölçülen her noktanın mesafeyle azalan bir etkiye sahip olduğunu varsayar. Öngörülen yere en yakın noktalara daha büyük ağırlıklar verir ve ağırlıklar mesafenin bir fonksiyonu olarak azalır ve bu nedenle ters mesafe ağırlıklı adı verilir. IDW aşağıdaki şekilde hesaplanır [19].

$$
V_{i}=\frac{\sum_{j=1}^{n} \frac{1}{d_{i j}{ }^{p}} V_{j}}{\sum_{j=1}^{n} \frac{1}{d_{i j}{ }^{p}}}
$$

Burada $V_{i}$ hesaplanmak istenen değer, n gözlem noktaların sayısı, $V_{j} j$. bilinen değer, $d_{i j} i$ ve $j$ bilinmeyen noktaları arasındaki mesafe ve p ise gözlemlerin her birinin atanmış ağırlığını belirleyen üstür.

IDW ile elde edilen yoğunluk ve kirlilik haritaları, jeoloji haritası ve bölgede yapılan önceki çalışmalar (jeoloji, hidrojeoloji ve maden yatakları) ile birlikte değerlendirilmiş, çalışma alanındaki yeraltı suyu kalitesi ve bunu etkileyen faktörlerin yorumlanması gerçekleştirilmiştir. 
Çalışmadaki haritaların üretilmesinde ve IDW yönteminin uygulanmasında ArcGIS Desktop 10.7 yazılımından yararlanılmıştır.

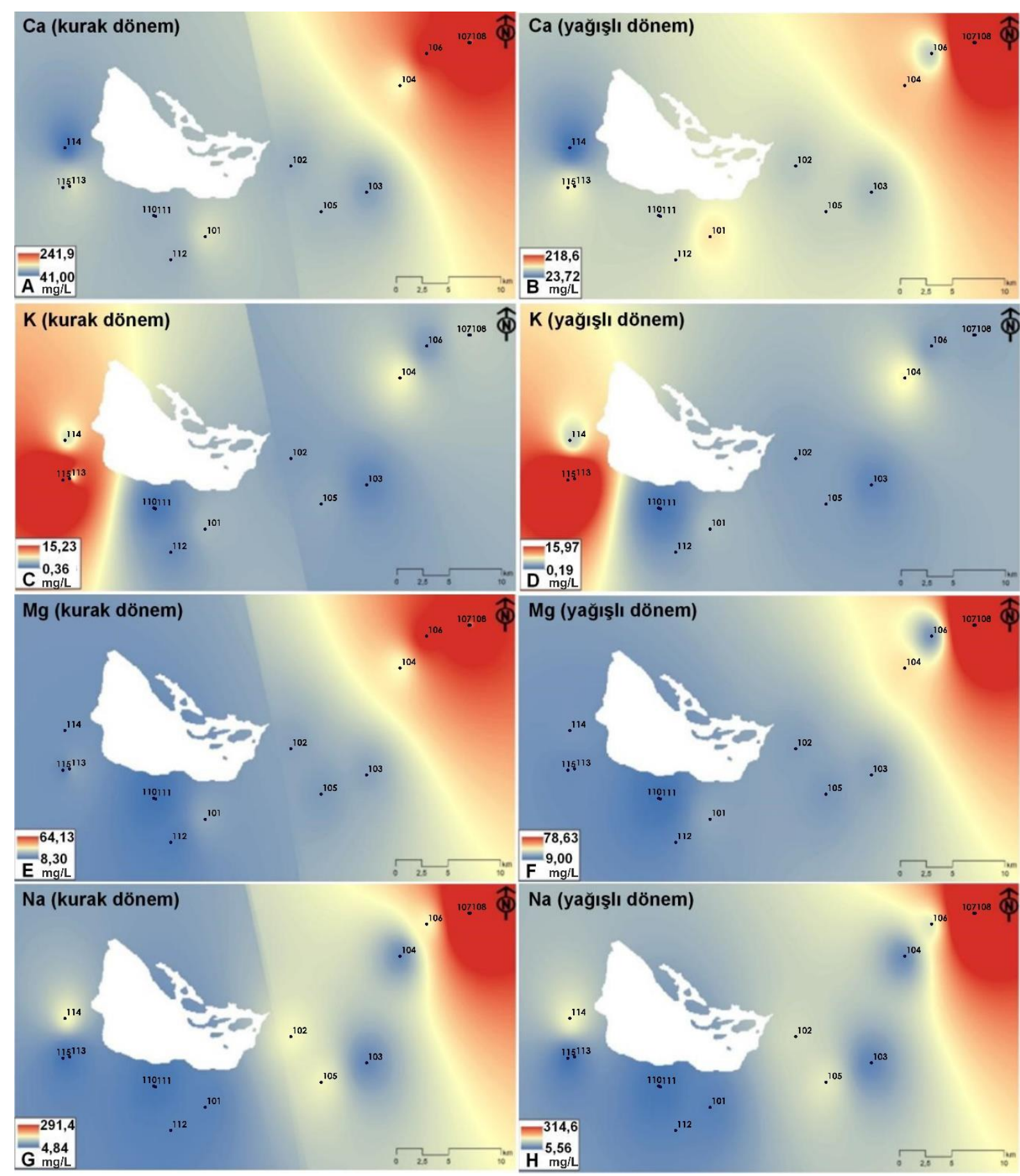

Şekil 4. Çalışma sahası anyon yoğunluk dağılım haritaları

\section{BULGULAR}

Çalışma alanındaki yeraltı sularının katyon yoğunluk haritaları incelediğinde $\mathrm{Ca}, \mathrm{Na}, \mathrm{Mg}$ elementlerinde çalışma alanının kuzey doğu bölgesinde yoğunlaşma düzeyinde artış gözlenirken K elementinde ise batı-güneybatı bölgesinde artış gözlenmiştir (Şekil 4). Bu 
yoğunlaşmaların nedeninin $\mathrm{Ca}, \mathrm{Na}, \mathrm{Mg}$ elementleri için çalışma alanının kuzeydoğusunda bulunan Kozaklı Kireçtaşı üyesi ve Mucur Tüf üyesine ait kayaçlardan kaynaklanabileceği, K element yoğunlaşmasının ise Kervansaraydağ formasyonu içerisindeki gnays ve şistler içerisindeki mika ve alkali feldispat minerallerine bağlı olabileceği düşünülmektedir.



Şekil 5. Çalışma sahası katyon yoğunluk dağılım haritaları

Çalışma alanındaki yeraltı sularının anyon yoğunluk haritaları incelediğinde $\mathrm{Cl}$ elementindeki artış Kızılırmak formasyonun bulunduğu orta- doğu kesimlerde gözlenmiştir. $\mathrm{SO}_{4}$ ve $\mathrm{F}$ 
elementleri ise kuzey doğu bölgesinde yoğunlaştığı gözlenmiş olup bunun nedeninin Kızılırmak formasyonu içeresindeki jipsli ve tuzlu seviyelerden kaynaklanabileceği düşünülmektedir (Şekil 5).

Bölge $\mathrm{NO}_{3}$ yoğunluğu açısından değerlendirildiğinde Kızılırmak formasyonu içerisindeki tarım alanlarının bulunduğu bölgelerde yoğunluk artışı gözlemlenmiş olup, nedeninin tarımda kullanılan gübrelerden kaynaklandığı düşünülmektedir.

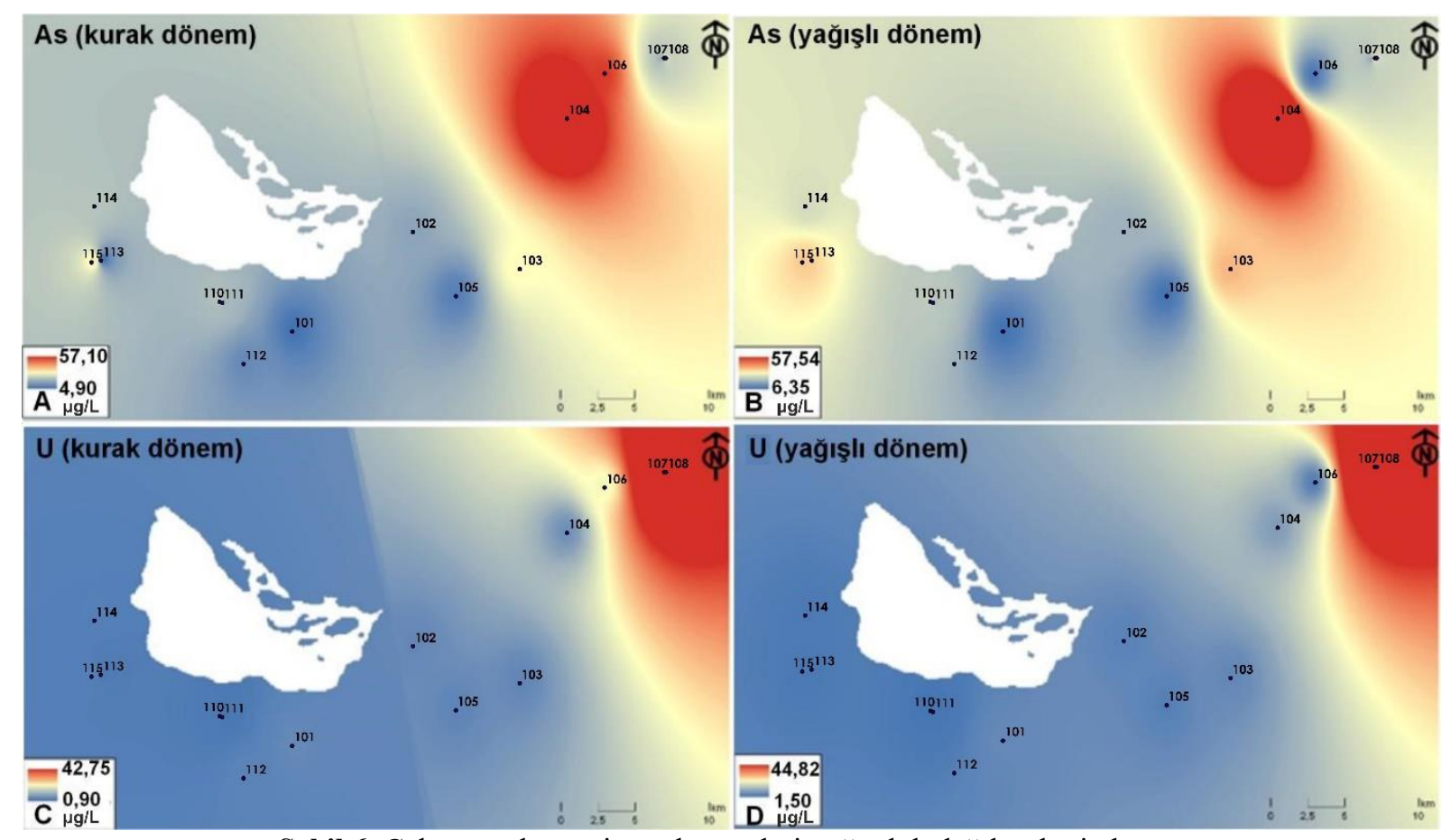

Şekil 6. Çalışma sahası minör elementleri yoğunluk dağılım haritaları

Bölgedeki yeraltı sularının minör elementlerden As ve U yoğunluk haritaları incelediğinde, kuzeydoğusunda yoğunlaştı̆̆ gözlenmiş olup Kozaklı Kireçtaşı üyesi ve Mucur Tüf üyesine ait kayaçların bu yoğunlaşmaya neden olabileceği düşünülmektedir (Şekil 6).

TS 266-2005 ve WHO-2006 standartlarına göre çalışma alanının yeraltı suyu kirliliği açısından eşik değerler ve eşik değeri aşan riskli bölgeleri Şekil 7'de belirlendiği gibidir. Bölgedeki yeraltı sularında $\mathrm{NO}_{3}, \mathrm{SO}_{4}, \mathrm{As}, \mathrm{F}$ ve $\mathrm{U}$ açısından kirlilikler tespit etmiştir. Şekil 7'de mavi olarak görülen alanlar TS 266-2005 ve WHO-2006 standartlarına göre içme suyu olarak kullanılmasında $\mathrm{NO}_{3}, \mathrm{SO}_{4}, \mathrm{As}, \mathrm{F}$ ve $\mathrm{U}$ açısından sakınca bulunmayan alanlardır. Bölgedeki kirliliğin nedenlerinin, kayaç litolojisi ile bilinçsiz olarak kullanılan gübre ve pestisitler olabileceği düşünülmektedir. 


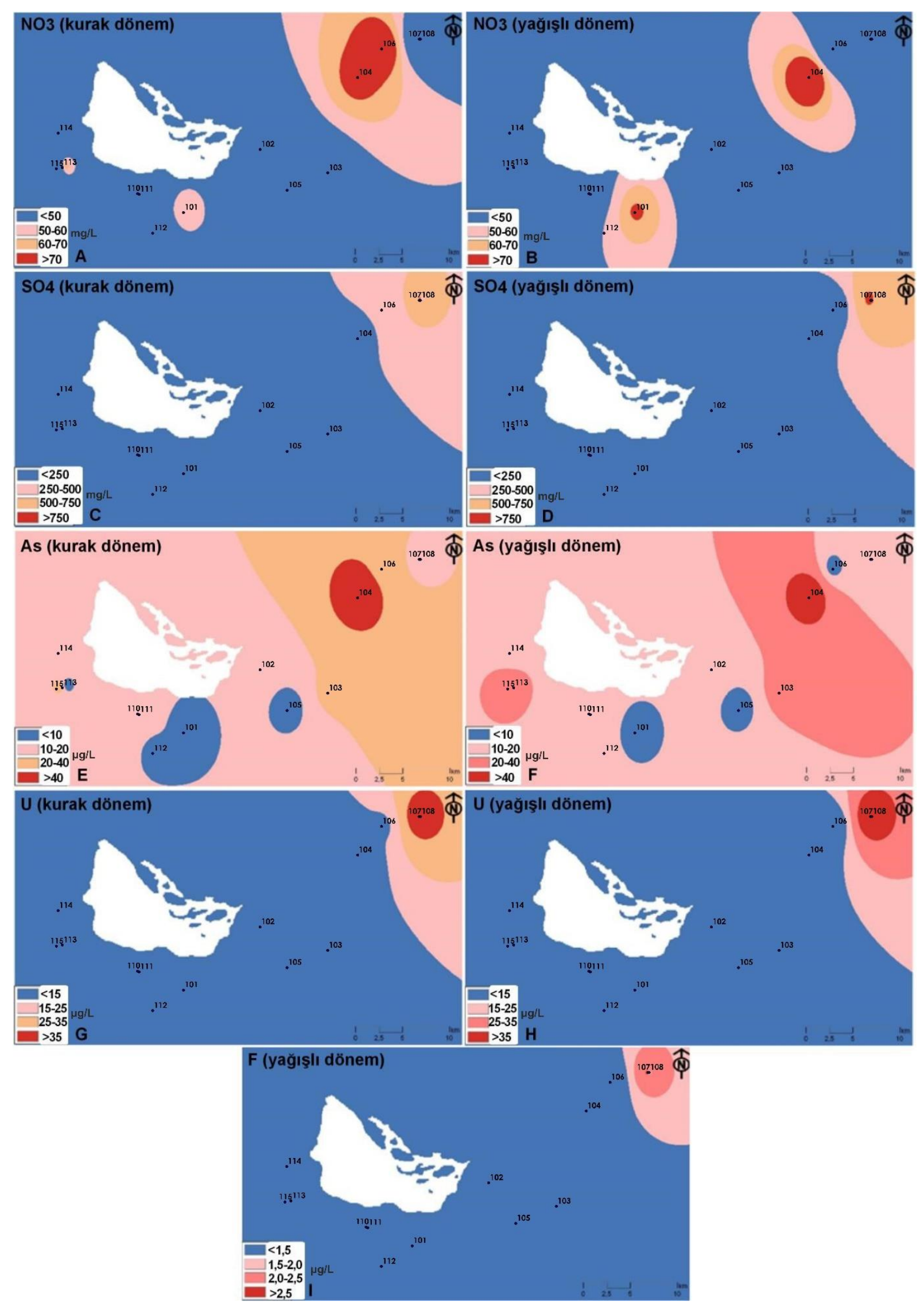

Şekil 7. Çalışma sahası yeraltı suyu kirlilik haritaları 


\section{SONUÇLAR}

Çalışma kapsamında Seyfe Gölü çevresi (Kırşehir) yeraltı suyu kalitesinin ve kirlenmesine neden olan unsurlar ile etki alanlarının belirlenmesi için klasik hidrojeoloji çalışmaları yanı sıra coğrafi bilgi sistemlerinin (CBS) kullanılması ile verilerin geniş alanlardaki su kalitesini gözlemlenmesi amaçlanmıştır.

İnceleme sahasındaki yeraltı sularının kimyasındaki değişikliklere neden olan en önemli etkenin kayaç litolojisi olduğu düşünülmektedir. $\mathrm{Ca}, \mathrm{Na}, \mathrm{Mg}$ ile $\mathrm{As}$ ve $\mathrm{U}$ yoğunluk değerlerindeki artışın çalışma alanının kuzeydoğu bölgesinde yaygın olarak bulunan Kozaklı Kireçtaşı üyesi ve Mucur Tüf üyesine ait kayaçlardan kaynaklandığı, K elementindeki artışın ise Kervansaray formasyonun yaygın olarak gözlendiği batı-güneybatı bölgesine ait kayaçlardan kaynaklandığı düşünülmektedir.

Kızılırmak formasyonu içeresindeki jipsli ve tuzlu seviyelerin bulunduğu inceleme alanının orta- doğu kesimlerinde $\mathrm{Cl}$, kuzey doğu bölgesinde $\mathrm{SO}_{4}$ ve $\mathrm{F}$ elementlerinin yoğunlaştığ1 gözlemlenmiştir. Ayrıca bölgedeki NO3 yoğunluğunun ise genellikle Kızılırmak formasyonu içerisinde bulunan tarım alanların da kullanılan gübrelerden kaynaklandığı düşünülmektedir.

Çalışma alanının yeraltı suyu kirliliği TS 266-2005 ve WHO-2006 standartlarına göre değerlendirildiğinde $\mathrm{NO}_{3}, \mathrm{SO}_{4}, \mathrm{As}, \mathrm{F}$ ve $\mathrm{U}$ açısından kirlilikler tespit etmiştir. Bölgedeki kirliliğin nedenlerinin, kayaç litolojisi ile bilinçsiz olarak kullanılan gübre ve pestisitler olabileceği düşünülmektedir.

Bölgedeki yer altı suyu kaynaklarının büyük oranda yağıştan beslenmesi nedeni ile yağışlı dönemlerde su kimyasında anyon, katyon ve minör element yoğunluklarında bir azalma gözlenmiştir.

Bölge su kalitesi açısından değerlendirildiğinde Bozçaldağ formasyonun (mermerler) yayılım gösterdiği alanlarda kirliliğin gözlenmediği belirlenmiştir. Gelecekte bölgede içme suyu olarak kullanılacak yeraltı suyunun temininde Bozçaldağ formasyonun bulunduğu alanların öncelikli olarak değerlendirilebileceği öngörülmektedir.

\section{Teşekkür}

Yazarlar, KMY.A3.17.001 no'lu bilimsel araştırma projesi ile desteklenen bu çalışmadan dolayı Kırşehir Ahi Evran Üniversitesi BAP birimine teşekkür ederler. 


\section{KAYNAKLAR}

[1] Fallahzadeh, R. A., Almodaresi, S. A., Dashti, M. M., Fattahi, A., Sadeghnia, M., Eslami, H., \& Taghavi, M. (2016). Zoning of nitrite and nitrate concentration in groundwater using Geografic information system (GIS), case study: drinking water wells in Yazd City. Journal of Geoscience and Environment Protection, 4(03), 91.

[2] Jhariya, D. C., Kumar, T., Dewangan, R., Pal, D., \& Dewangan, P. K. (2017). Assessment of groundwater quality index for drinking purpose in the Durg district, Chhattisgarh using Geographical Information System (GIS) and Multi-Criteria Decision Analysis (MCDA) techniques. Journal of the Geological Society of India, 89(4), 453-459.

[3] Neshat, A., Pradhan, B. (2017). Evaluation of groundwater vulnerability to pollution using DRASTIC framework and GIS. Arabian Journal of Geosciences, 10(22), 501.

[4] Tiwari, A. K., Singh, A. K., \& Mahato, M. K. (2017). GIS based evaluation of fluoride contamination and assessment of fluoride exposure dose in groundwater of a district in Uttar Pradesh, India. Human and Ecological Risk Assessment: An International Journal, 23(1), 56-66.

[5] Aminu, M., Matori, A. N., Yusof, K. W., Malakahmad, A., \& Zainol, R. B. (2015). A GIS-based water quality model for sustainable tourism planning of Bertam River in Cameron Highlands, Malaysia. Environmental Earth Sciences, 73(10), 6525-6537.

[6] Şener, Ş., Şener, E., \& Davraz, A. (2017). Evaluation of water quality using water quality index (WQI) method and GIS in Aksu River (SW-Turkey). Science of the Total Environment, 584, 131-144.

[7] El-Zeiny, A., \& El-Kafrawy, S. (2017). Assessment of water pollution induced by human activities in Burullus Lake using Landsat 8 operational land imager and GIS. The Egyptian Journal of Remote Sensing and Space Science, 20, S49-S56

[8] Yazidi, A., Saidi, S., Mbarek, N. B., \& Darragi, F. (2017). Contribution of GIS to evaluate surface water pollution by heavy metals: Case of Ichkeul Lake (Northern Tunisia). Journal of African Earth Sciences, 134, 166-173.

[9] Yeşilkanat, C., Kobya, Y., Taşkın, H., \& Çevik, U. (2014). Jeoistatistik Tahmin ve Simülasyon Yöntemleri ile Artvin İlindeki Doğal Kaynak Suları için Toplam Alfa ve Toplam Betanın Ara Değer Modellemesi ve Haritalanması. Cumhuriyet Üniversitesi FenEdebiyat Fakültesi Fen Bilimleri Dergisi, 35(4), 11-35.

[10] Mehrjardi, R.T., A. Akbarzadeh, S. Mahmoodi, A. Heidari and F. Sarmadian, (2008). Application of geostastical methods for mapping groundwater quality in Azarbayjan Province, Iran. Am. Eurasian J. Agric. Environ. Sci., 3: 726-735.

[11] Dagostino, V., E.A. Greene, G. Passarella and M. Vurro, (1998). Spatial and temporal study of nitrate concentration in groundwater by means of coregionalization. Environmental Geology, 36: 285-295. 
[12] Asadi, S. S., Vuppala, P., \& Reddy, M. A. (2007). Remote sensing and GIS techniques for evaluation of groundwater quality in municipal corporation of Hyderabad (Zone-V), India. International journal of environmental research and public health, 4(1), 45-52.

[13] Çelik, M., Ünsal, N., Tüfenkçi, O. O., Bolat, S. (2008). Assessment of water quality and pollution of the Lake Seyfe basin, Kirşehir, Turkey. Environmental geology, 55(3), 559569.

[14] Seymen, İ. (1981). Kaman (Kırşehir) dolayında Kırşehir masifinin stratigrafisi ve metamorfizması. Türkiye Jeoloji Bülteni, 24, 2, 101-108.

[15] Kara, H. (1991). 1:100.000 ölçekli açınsama nitelikli Türkiye jeoloji Haritaları serisi, Kırşehir-G 18 paftası. MTA yayınları.

[16] Kara, H., (1997). 1:100.000 ölçekli açınsama nitelikli Türkiye jeoloji Haritaları serisi, Kırşehir-G 19 paftası. MTA yayınları.

[17] TS 266 (2005). Türk Standartları Enstitüsü (TSE), Sular - İnsani tüketim amaçlı sular, Ankara.

[18] WHO (2006). "Guidelines for Drinking- Water Quality", First Addendum To Third Edition, 1, Recommendation, Geneva Switzerland.

[19] Shepard, D. (1968). A two-dimensional interpolation function for irregularly-spaced data. In Proceedings of the 1968 23rd ACM national conference (pp. 517-524). ACM. 